\title{
Simple Cystatin C Formula Compared to Serum Creatinine-Based Formulas for Estimation of Glomerular Filtration Rate in Patients with Mildly to Moderately Impaired Kidney Function
}

\author{
Sebastjan Bevc ${ }^{\mathrm{a}}$ Radovan Hojs ${ }^{\mathrm{a}}$ Robert Ekart ${ }^{\mathrm{a}}$ Maksimiljan Gorenjak ${ }^{\mathrm{c}}$ \\ Ludvik Puklavec ${ }^{\text {b }}$ \\ Departments of a Nephrology and ${ }^{b}$ Nuclear Medicine, Clinic of Internal Medicine, and ${ }^{c}$ Department of \\ Clinical Chemistry, University Medical Center Maribor, Maribor, Slovenia
}

\section{Key Words}

${ }^{51}$ Cr-EDTA clearance $\cdot$ Chronic kidney disease $\cdot$ Glomerular filtration rate $\cdot$ Serum creatinine-based equations $\cdot$ Serum cystatin C-based equation

\begin{abstract}
Background: Serum cystatin C (SCC)-based formulas and the newer creatinine formula (the Chronic Kidney Disease Epidemiology Collaboration formula (CKD-EPI)) were proposed as improved glomerular filtration rate (GFR) markers. The aim of our study was to compare serum creatinine ( $\mathrm{SCr}$ )based and SCC-based equations against ${ }^{51} \mathrm{Cr}$-EDTA clearance in patients with mildly to moderately impaired kidney function. Methods: 255 adult Caucasian patients with chronic kidney disease (GFR 89-30 ml/min/1.73 $\mathrm{m}^{2}$ ) were enrolled. In each patient, ${ }^{51} \mathrm{Cr}$-EDTA clearance, $\mathrm{SCr}$ and SCC were determined. GFR was calculated using the Cockcroft-Gault (C\&G), Modification of Diet in Renal Disease (MDRD), CKD-EPI formulas and simple cystatin C formula (SCCF) (100/SCC). $\boldsymbol{R e}$ sults: The receiver-operating characteristic curve analysis (cut-off for GFR $60 \mathrm{ml} / \mathrm{min} / 1.73 \mathrm{~m}^{2}$ ) showed that the SCCF had a higher diagnostic accuracy than C\&G but not than MDRD or CKD-EPI formulas. The Bland-Altman analysis for the same cut-off value showed that creatinine formulas un-
\end{abstract}

\section{KARGER}

Fax +41613061234 E-Mail karger@karger.ch www.karger.com
(C) 2012 S. Karger AG, Basel

$1420-4096 / 12 / 0356-0649 \$ 38.00 / 0$

Accessible online at:

www.karger.com $/ \mathrm{kbr}$ derestimated and SCCF overestimated the measured GFR. Analysis of ability to correctly predict a patient's GFR $<60$ or $>60 \mathrm{ml} / \mathrm{min} / 1.73 \mathrm{~m}^{2}$ showed the higher ability for the SCCF compared to all creatinine-based formulas. Conclusion: Our results indicate that the SCCF is a reliable marker of GFR and comparable to creatinine formulas including the CKD-EPI formula.

Copyright $\odot 2012$ S. Karger AG, Basel

\section{Introduction}

Chronic kidney disease (CKD) is an important public health problem. CKD is defined as kidney damage or a glomerular filtration rate $(\mathrm{GFR})<60 \mathrm{ml} / \mathrm{min} / 1.73 \mathrm{~m}^{2}$ for 3 months or more, irrespective of cause, and is classified into stages according to the level of GFR. Therefore, GFR estimation is essential for the evaluation of patients with CKD. GFR estimation allows us to detect early impairment of kidney function, prevent further deterioration and complications, to correct the dosage of drugs cleared by the kidney so as to avoid potential drug toxicity and to help us to manage CKD patients. The National Kidney Disease Education Program (NKDEP) recommended reporting GFR values $>60 \mathrm{ml} / \mathrm{min} / 1.73 \mathrm{~m}^{2}$ not as an exact 
number but simply as $>60 \mathrm{ml} / \mathrm{min} / 1.73 \mathrm{~m}^{2}$, and contrary for the values of $60 \mathrm{ml} / \mathrm{min} / 1.73 \mathrm{~m}^{2}$ and below the exact numerical estimate should be reported [1]. For clinicians the GFR $<60 \mathrm{ml} / \mathrm{min} / 1.73 \mathrm{~m}^{2}$ is very important. The values indicate the presence of CKD and represent an increased risk of impaired kidney function, progression to kidney failure and premature death caused by cardiovascular events of CKD patients $[2,3]$.

Over the last decades several different markers for GFR estimation have been proposed. The ideal marker of GFR should be an endogenous molecule which, being produced at a constant rate, is cleared solely by the kidneys via free glomerular filtration, without being either secreted by tubular cells or reabsorbed into peritubular circulation [4]. The 'gold standard' for GFR estimation is clearance of exogenous substances such as inulin, iohexol, ${ }^{51} \mathrm{Cr}$-EDTA, ${ }^{99 \mathrm{~m}} \mathrm{Tc}-\mathrm{DTPA}$ or ${ }^{125} \mathrm{I}$-iothalamate. These techniques are time-consuming, labor-intensive, and expensive and require administration of substances that make them incompatible with routine monitoring.

Despite all known disadvantages, serum creatinine ( $\mathrm{SCr}$ ) concentration has become the most commonly used marker to estimate GFR in clinical practice as in most studies [5]. The current Kidney Disease Outcomes Quality Initiative (K/DOQI) guidelines emphasize the need to assess kidney function using predictive equations, such as the Cockcroft-Gault (C\&G) formula and abbreviated Modification of Diet in Renal Disease (MDRD) formula, rather than just SCr [6, 7]. Unfortunately, all these formulas are also limited by lack of validation in the full range of GFR to which they are applied [8]. To minimize some of these limitations, such as imprecision and systematic underestimation of the measured GFR with MDRD formula, the new Chronic Kidney Disease Epidemiology Collaboration equation (CKDEPI formula) was developed [9]. The authors of the new equation validated the CKD-EPI equation using data pooled from several previous studies and showed that the new formula is more accurate than the widely used MDRD formula [9]. Common features of these equations are reliance on SCr and demographic and anthropometric data, and the accuracy of these formulas is still debated $[6,8]$.

Recently, serum cystatin C (SCC) was proposed as a new endogenous marker of GFR. This protease inhibitor with a low molecular weight is produced at a constant rate by all nucleated cells. It is freely filtered across the glomerular membrane and is reabsorbed and metabolized in the proximal tubule $[10,11]$. The previous reports have suggested that a SCC concentration is a better indicator of GFR than a SCr concentration in patients with spine injury, liver cirrhosis, diabetes, mildly to moderately impaired kidney function, and in elderly patients [12-14]. Over the last few years, several SCC-based equations (cystatin C formulas) have been developed and proposed to estimate the GFR from SCC concentration as an alternative filtration marker to SCr-based equations [15-21].

The aim of our study was to compare three SCr-based equations (C\&G, MDRD and CKD-EPI formulas) and the simple cystatin $\mathrm{C}$ equation against ${ }^{51} \mathrm{Cr}$-EDTA clearance in a population of patients with mildly to moderately impaired kidney function.

\section{Patients and Methods}

In this study, 255 adult Caucasian patients (118 women and 137 men) with mildly to moderately (GFR $89-30 \mathrm{ml} / \mathrm{min} / 1.73 \mathrm{~m}^{2}$ ) impaired kidney function were included. All patients were referred for ${ }^{51} \mathrm{Cr}$-EDTA clearance by nephrologists, diabetologists, cardiologists or general internists because of suspected or established renal dysfunction. At the same time as ${ }^{51} \mathrm{Cr}$-EDTA clearance was estimated, both SCr and SCC were measured. SCr was measured by using the kinetic method according to the Jaffé method without deproteinization (isotope dilution mass spectrometry traceable creatinine assay) (Roche Diagnostics). This is a compensated method based on the manufacturer's instructions and was described previously [22]. SCC was measured by the particle-enhanced immunonephelometric method (Dade Behring). The GFR was estimated from a single ${ }^{51} \mathrm{Cr}$-EDTA injection and three blood samples $(120,180$ and $240 \mathrm{~min}$ after parenteral application of the marker) according to the Committee on Renal Clearance Recommendations [23]. At the time of blood sample collection there were no clinically relevant signs of inflammation observed in the enrolled patients.

${ }^{51} \mathrm{Cr}$-EDTA clearance was calculated in milliliters per minute per $1.73 \mathrm{~m}^{2}$. The GFR was calculated according to C\&G (I), MDRD (II) and CKD-EPI (III) formulas:

I. GFR calculated according to the C\&G formula:

$[140$ - age (years) $\times$ body weight $(\mathrm{kg}) /[0.815 \times \mathrm{SCr}(\mu \mathrm{mol} / \mathrm{l})]$

The correction factor of 0.85 was used for women.

II. GFR calculated according to the MDRD formula:

$175 \times \mathrm{SCr}(\mathrm{mg} / \mathrm{dl})^{-1.154} \times$ age $(\text { years })^{-0.203}$

The correction factor of 0.742 was used for women.

III. GRF calculated according to the CKD-EPI formula:

$\mathrm{GFR}=a \times(\mathrm{SCr}(\mathrm{mg} / \mathrm{dl}) / b)^{c} \times(0.993)^{\mathrm{age}}$

The variable $a$ takes on the following values on the basis of race and sex:

- Black women $=166 ;$ black men $=164 ;$ white/other women $=$ 144; white/other men $=141$.

The variable $b$ takes on the following values on the basis of sex:

- Women $=0.7$; men $=0.9$.

The variable $c$ takes on the following values on the basis of sex and creatinine measurement:

- Women: SCr $\leq 0.7 \mathrm{mg} / \mathrm{dl}=-0.329 ; \mathrm{SCr}>0.7 \mathrm{mg} / \mathrm{dl}=-1.209$,

- Men: SCr $\leq 0.7 \mathrm{mg} / \mathrm{dl}=-0.411 ; \mathrm{SCr}>0.7 \mathrm{mg} / \mathrm{dl}=-1.209$. 
The C\&G formula was standardized for a $1.73-\mathrm{m}^{2}$ body surface area (according to the DuBois \& DuBois method). The MDRD formula and CKD-EPI formulas are already standardized for a $1.73-\mathrm{m}^{2}$ body surface area.

GFR was also calculated according to a previously published simple cystatin C formula (SCCF) (IV) [24]:

IV. GFR calculated according to the SCCF:

100/SCC (mg/l).

For statistical analysis, SPSS for Windows (version 12.0.1) and MedCalc for Windows (version 5.00.020) were used. The mean values, range and SD were calculated. Pearson's correlation coefficient was used for defining the correlation between ${ }^{51} \mathrm{Cr}$-EDTA clearance and SCr, SCC, the GFR calculated from the SCr-based formula and the GFR calculated from the cystatin C formula. In order to determine the diagnostic accuracy of the SCC-based formula in comparison with the other markers of GFR, receiveroperating characteristic (ROC) plots were constructed and analyzed. The area under the curve describes the test's overall performance and is used to compare different tests. Sensitivity and specificity were calculated. The GFR determined with ${ }^{51} \mathrm{Cr}$ EDTA clearance was used as the gold standard and the cut-off value was set at $60 \mathrm{ml} / \mathrm{min} / 1.73 \mathrm{~m}^{2}$ for CKD as defined by the National Kidney Foundation [6]. To compare the creatininebased estimations of the GFR (C\&G, MDRD and CKD-EPI formulas) with ${ }^{51} \mathrm{Cr}$-EDTA clearance and the SCC-based estimation, Bland-Altman plots were used [25]. The mean difference between estimated and measured GFR values estimates the global bias. The width of SD of the mean difference is an estimation of precision. The accuracy within $30 \%$ for different equations was measured as the percentage of results that did not deviate more than $30 \%$ from the measured GFR with ${ }^{51} \mathrm{Cr}$-EDTA clearance. The accuracy within $30 \%$ of both stages of CKD was analyzed. The ability to correctly estimate the patient's GFR $<60$ and $>60 \mathrm{ml} / \mathrm{min} / 1.73 \mathrm{~m}^{2}$ with different equations compared to the 'gold standard' was also analyzed.

The study protocol was in conformity with ethical guidelines and informed consent was obtained from each participant.

\section{Results}

The baseline characteristics of the patients studied are presented in table 1 . The age of patients ranged from 18 to 86 years (mean $59.7 \pm 14.1$ ), heights ranged from 142 to $187 \mathrm{~cm}$ (mean $168.5 \pm 9$ ), mean weight was $78.3 \pm$ $14.7 \mathrm{~kg}$ (range 46-142), and mean body mass index was $27.6 \pm 4.7 \mathrm{~kg} / \mathrm{m}^{2}$ (women $26.8 \pm 5.2$, men $28.2 \pm 4.1$ ). Diabetes was present in $12.5 \%$ of patients $(n=32)$. The mean ${ }^{51} \mathrm{Cr}$-EDTA clearance in our patients was $55.5 \mathrm{ml} /$ $\min / 1.73 \mathrm{~m}^{2}$. The mean $\mathrm{SCr}$ concentration value was $148.1 \mu \mathrm{mol} / \mathrm{l}(61-651 \mu \mathrm{mol} / \mathrm{l}$; SD \pm 58$)$. The SCC concentration values were between 0.59 and $5.37 \mathrm{mg} / \mathrm{l}$ (mean $1.73 \mathrm{mg} / \mathrm{l}$; SD \pm 0.7 ). A statistically significant correlation was found between ${ }^{51} \mathrm{Cr}$-EDTA clearance and SCC $(\mathrm{r}=-0.665 ; \mathrm{p}<0.0001), \mathrm{SCr}(\mathrm{r}=-0.516 ; \mathrm{p}<0.0001)$ and
Table 1. Patients' baseline characteristics

\begin{tabular}{ll}
\hline Number of cases & 255 \\
Males/females & $137 / 118$ \\
Mean age \pm SD, years & $59.7 \pm 14.1$ \\
Mean body mass index \pm SD & $27.6 \pm 4.7$ \\
Diabetes patients, $\mathrm{n}(\%)$ & $32(12.5)$ \\
Mean SCr $\pm \mathrm{SD}, \mu \mathrm{mol} / \mathrm{l}$ & $148.1 \pm 58$ \\
Mean SCC $\pm \mathrm{SD}, \mathrm{mg} / \mathrm{l}$ & $1.73 \pm 0.7$ \\
\hline
\end{tabular}

Table 2. Diagnostic accuracy (area under the ROC curves, sensitivity, specificity) and comparison of ROC curves at a cut-off value for GFR $60 \mathrm{ml} / \mathrm{min} / 1.73 \mathrm{~m}^{2}$ of calculated clearance from the C\&G, MDRD and CKD-EPI formulas and SCCF

\begin{tabular}{lllll}
\hline Equation & AUC & $\begin{array}{l}\text { Sensi- } \\
\text { tivity, \% }\end{array}$ & $\begin{array}{l}\text { Speci- } \\
\text { ficity, \% }\end{array}$ & $\begin{array}{l}\mathrm{p} \\
\text { value* }\end{array}$ \\
\hline C\&G formula & 0.795 & 69.5 & 80.8 & 0.0001 \\
MDRD formula & 0.890 & 82.8 & 85.6 & 0.376 \\
CKD-EPI formula & 0.890 & 84.1 & 84.6 & 0.371 \\
SCCF & 0.911 & 80.8 & 88.5 & \\
\hline
\end{tabular}
dard.

GFR determined with ${ }^{51} \mathrm{Cr}$-EDTA was used as the gold stan-

* Calculated according to the SCCF.

with GFR calculated from the C\&G formula $(\mathrm{r}=0.554$; $\mathrm{p}<0.0001)$, the MDRD formula $(\mathrm{r}=0.711 ; \mathrm{p}<0.0001)$, the CKD-EPI formula ( $\mathrm{r}=0.710 ; \mathrm{p}<0.0001)$, and the SCCF $(r=0.759 ; p<0.0001)$. In a comparison of the correlation coefficients, we found that the correlations between ${ }^{51} \mathrm{Cr}$-EDTA clearance and SCCF and ${ }^{51} \mathrm{Cr}$-EDTA clearance and the MDRD formula or the CKD-EPI formula and ${ }^{51} \mathrm{Cr}$-EDTA clearance were superior to the correlation between ${ }^{51} \mathrm{Cr}$-EDTA clearance and the C\&G formula ( $p=0.00001$ for SCCF, $p=0.0029$ for the MDRD formula and $\mathrm{p}=0.0031$ for the CKD-EPI formula). No difference between correlation coefficients of the MDRD or CKD-EPI formulas and SCCF was found ( $\mathrm{p}=0.2401$ and $\mathrm{p}=0.2312$ ). Diagnostic accuracy (area under the ROC curves, sensitivity and specificity) at the cut-off value for GFR $60 \mathrm{ml} / \mathrm{min} / 1.73 \mathrm{~m}^{2}$ of the different creatinine-based equations and the simple cystatin C-based equation are presented in table 2 . The ROC curve analysis (cut-off for GFR $60 \mathrm{ml} / \mathrm{min} / 1.73 \mathrm{~m}^{2}$ ) showed that the SCCF had a significantly higher diagnostic accuracy than the $C \& G$ formula ( $p<0.0001$ ) (table 2 ; fig. 1 ). No difference in diagnostic accuracy was found between the SCCF and MDRD ( $\mathrm{p}=0.376$ ) or CKD-EPI formulas 
Table 3. Bias, precision (cut-off value for GFR $60 \mathrm{ml} / \mathrm{min} / 1.73 \mathrm{~m}^{2}$ ) and ability to correctly predict patient's GFR according to ${ }^{51} \mathrm{Cr}$ EDTA clearance in 255 patients with mildly to moderately impaired kidney function

\begin{tabular}{lcll}
\hline Equation & $\begin{array}{l}\text { Bias } \\
\mathrm{ml} / \mathrm{min} / \\
1.73 \mathrm{~m}^{2}\end{array}$ & $\begin{array}{l}\text { Precision } \\
\mathrm{ml} / \mathrm{min} / \\
1.73 \mathrm{~m}^{2}\end{array}$ & $\begin{array}{l}\text { Ability to correctly } \\
\text { predict patient's } \\
\mathrm{GFR}<60 \text { or }>60 \\
\mathrm{ml} / \mathrm{min} / 1.73 \mathrm{~m}^{2}\end{array}$ \\
\hline C\&G formula & -2.7 & 23.6 & $73.7 \%$ \\
MDRD formula & -23.2 & 11.6 & $64.7 \%$ \\
CKD-EPI formula & -19.9 & 12.7 & $67.1 \%$ \\
SCCF & 9.0 & 17.6 & $79.6 \%$
\end{tabular}

Table 4. Accuracy of formulas within $30 \%$ of estimated ${ }^{51} \mathrm{Cr}$ EDTA clearance values for stages 2 and 3 of CKD

\begin{tabular}{|c|c|c|}
\hline & Stage 2 of CKD & Stage 3 of $C K D$ \\
\hline Patients, $\mathrm{n}$ & 104 & 151 \\
\hline $\mathrm{GFR}, \mathrm{ml} / \mathrm{min} / 1.73 \mathrm{~m}^{2}$ & $60-89$ & $30-59$ \\
\hline Equation & $\begin{array}{l}\text { Accuracy } \\
\text { for stage } 2\end{array}$ & $\begin{array}{l}\text { Accuracy } \\
\text { for stage } 3\end{array}$ \\
\hline C\&G formula & $73.1 \%$ & $57.0 \%$ \\
\hline MDRD formula & $51.0 \%$ & $78.1 \%$ \\
\hline CKD-EPI formula & $48.1 \%$ & $74.8 \%$ \\
\hline SCCF & $83.7 \%$ & $53.6 \%$ \\
\hline
\end{tabular}

$(\mathrm{p}=0.371)$. The Bland-Altman analysis for the same cutoff value showed that creatinine formulas ( $C \& G$ formula bias: $-2.7 \mathrm{ml} / \mathrm{min} / 1.73 \mathrm{~m}^{2}$; MDRD formula bias: -23.2 $\mathrm{ml} / \mathrm{min} / 1.73 \mathrm{~m}^{2}$; CKD-EPI formula $-19.9 \mathrm{ml} / \mathrm{min} /$ $1.73 \mathrm{~m}^{2}$ ) underestimated and the SCCF (bias: $9 \mathrm{ml} / \mathrm{min} /$ $1.73 \mathrm{~m}^{2}$ ) overestimated the measured GFR. Analysis of the SD of the mean difference between the estimated and measured GFR showed that all equations lacked precision. It was $23.6,11.6$ and $12.7 \mathrm{ml} / \mathrm{min} / 1.73 \mathrm{~m}^{2}$ for the C\&G, MDRD and CKD-EPI formulas and $17.6 \mathrm{ml} /$ $\mathrm{min} / 1.73 \mathrm{~m}^{2}$ for SCCF (table 3).

The accuracy within $30 \%$ of estimated ${ }^{51} \mathrm{Cr}$-EDTA clearance values differ according to stages of CKD (table 4). In patients with mildly impaired kidney function a statistically significant higher accuracy within $30 \%$ was found for SCCF (83.7\%) compared to accuracy for the MDRD formula (51\%) or the CKD-EPI formula $(48.1 \%)(p<0.0005)$. On the contrary, in patients with moderately impaired kidney function a statistically sig-

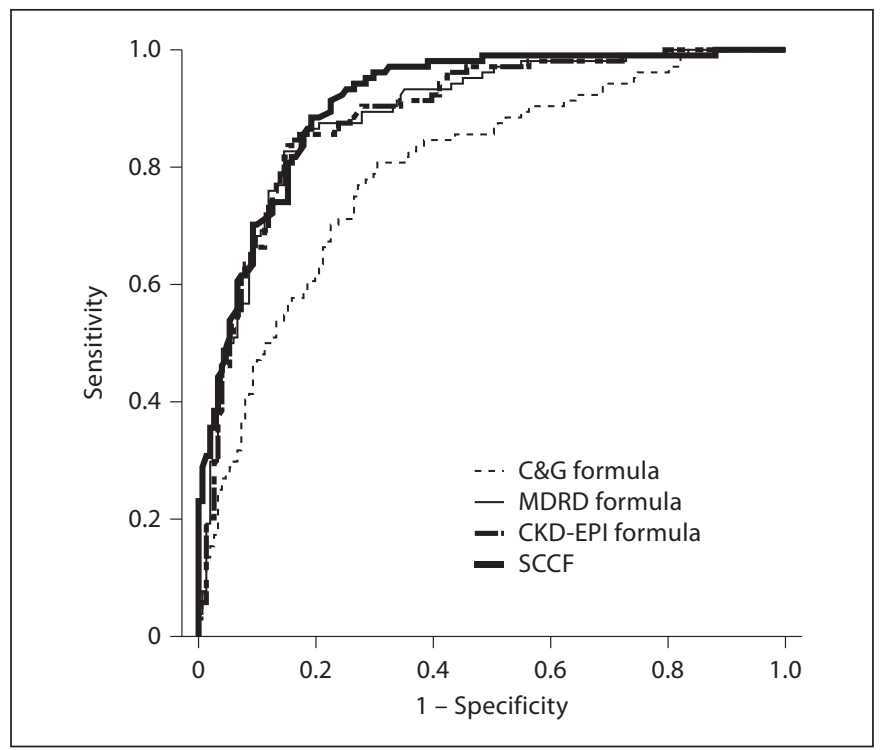

Fig. 1. ROC curve analysis of diagnostic accuracy of calculated clearance from the C\&G, MDRD and CKD-EPI formulas and SCCF. The GFR determined with ${ }^{51} \mathrm{Cr}$-EDTA was used as the gold standard and the cut-off value was set at $60 \mathrm{ml} / \mathrm{min} / 1.73 \mathrm{~m}^{2}$.

nificant higher accuracy within 30\% was found for the MDRD formula (78.1\%) or the CKD-EPI formula (74.8\%) compared to accuracy for SCCF (53.6\%) ( $\mathrm{p}<$ 0.0005).

Analysis of ability to correctly predict a patient's GFR $<60$ or $>60 \mathrm{ml} / \mathrm{min} / 1.73 \mathrm{~m}^{2}$ showed the higher ability for SCCF compared to all creatinine-based formulas, and the differences were statistically significant for the MDRD formula ( $\mathrm{p}<0.0005)$ or the CKD-EPI formula $(\mathrm{p}<$ 0.0027), but not for the $C \& G$ formula $(p=0.1512)$ (table 3).

\section{Discussion}

The current guidelines emphasize the need to assess kidney function using the predictive creatinine-based equations rather than just SCr [6]. The C\&G and MDRD formulas have been evaluated in numerous previously published studies. The formulas have been widely applied, but some studies reported limitations [3]. Therefore, a new creatinine-based CKD-EPI equation was developed [9]. Recently, some new cystatin C formulas were also developed, compared with creatinine formulas and proposed as an alternative filtration marker to creatinine $[16,17,20,21,26,27]$. In our study, we compared all three 
widely used creatinine-based equations and one very simple cystatin C-based equation in well-defined patients with mildly to moderately impaired kidney function. We have shown that the SCCF achieved at least as good a diagnostic performance as the creatinine formulas, including a newer CKD-EPI formula. Some other studies on populations with CKD showed a higher accuracy of the cystatin $\mathrm{C}$ formulas compared to the $\mathrm{C} \& \mathrm{G}$ and MDRD formulas $[16,17]$. Some authors even concluded that the cystatin C formula is complementary to the SCr-based equations or can be used in place of the SCr-based equations [20, 21]. Levey et al. [9] showed that the CKD-EPI creatinine-based equation is more accurate than the MDRD study equation across various study populations and clinical conditions, but no such data are available for the CKD-EPI formula compared to SCC-based equations. In our present study in a population of patients with mildly to moderately impaired kidney function, the correlation between the 'gold standard', ${ }^{51} \mathrm{Cr}$-EDTA clearance and the SCCF was better than the correlation between the ${ }^{51} \mathrm{Cr}$-EDTA clearance and GFR calculated with the C\&G formula. No difference between correlation coefficients of the MDRD formula or the CKD-EPI formula and the SCCF was found. According to our results, the SCCF had a significantly higher diagnostic accuracy for a clinically important cut-off value for GFR $60 \mathrm{ml} /$ $\min / 1.73 \mathrm{~m}^{2}$ than the C\&G formula. No difference in diagnostic accuracy between the SCCF and creatinine clearance calculated from the MDRD or CKD-EPI formulas was found. The Bland-Altman analysis for the same cut-off value showed that all three creatinine-based formulas underestimated the measured GFR $\left({ }^{51} \mathrm{Cr}\right.$-EDTA clearance). On the contrary, the SCCF overestimated the measured GFR. The accuracy within $30 \%$ of the estimated gold standard values demonstrated SCCF's superiority compared to the MDRD and CKD-EPI formulas only in patients with mildly impaired kidney function. Furthermore, in the analysis of the ability to correctly predict a patient's GFR $<60$ or $>60 \mathrm{ml} / \mathrm{min} / 1.73 \mathrm{~m}^{2}$, the higher ability for the SCCF compared to all creatinine-based formulas was found.

The results of the present study suggest that the cystatin C-based prediction equation, which requires just one variable (SCC concentration), achieved a diagnostic performance that was at least as good as the creatinine formulas using more variables. In our well-defined patients with CKD stage 2-3, the SCCF had a higher diagnostic accuracy in distinguishing patients with mildly to moderately impaired kidney function than the calculated clearance from the $C \& G$ formula. The newest sophisti- cated CKD-EPI formula, like C\&G and MDRD formulas, requires additional calculator equipment which is superfluous when SCCF is used.

Our study has some potential limitations. First, the results of the present study only analyze a Caucasian population. The creatinine-based equations were developed from studies which involved participants of all races. Thus, a direct comparison of equations can only be performed between the CKD-EPI formula (equation includes a variable on the basis of race) and SCCF. Second, the above-mentioned studies were performed with different GFR references and gold standards. Some authors used ${ }^{125}$ I-iothalamate $[9,16,24]$ and others used iohexol $[15,21]$ as the 'gold standard' to measure GFR. In our study, ${ }^{51} \mathrm{Cr}$-EDTA clearance was used for GFR estimation. Therefore, an exact direct comparison between these studies is difficult. Third, in our study the SCC and SCr were measured only once, so we cannot rule out any known intra-patient variability of SCr or SCC concentration which can be present due to production and/or extrarenal elimination. Finally, the cause of kidney damage in patients with CKD stage 2-3 was not analyzed.

In conclusion, our study has demonstrated that SCCF could be a useful tool for evaluation of renal function in patients with mildly to moderately impaired kidney function in daily clinical practice in hospital and especially in outpatients. Despite the advantages of SCCF, cystatin Cbased equations cannot completely replace the 'gold standard' for GFR estimation in a population with CKD, but may contribute to a more accurate selection of patients requiring such invasive and costly procedures. Further research is also needed to evaluate the SCCF on other representative samples, in particular elderly persons, patients with diabetic nephropathy, and other non-Caucasian populations.

\section{Acknowledgment}

This study was supported by grant L3-0328 from the Slovenian Research Agency (ARRS).

\section{Disclosure Statement}

The authors have no conflicts of interest to disclose. 


\section{References}

-1 Myers GL, Miller WG, Coresh J, Fleming J, Greenberg N, Greene T, et al: Recommendations for improving serum creatinine measurement: a report from the Laboratory Working Group of the National Kidney Disease Education Program. Clin Chem 2006; 52:5-18.

-2 Go AS, Chertow GM, Fan D, McCulloch CE, McCulloch CE, Hsu CY: Chronic kidney disease and the risk of death, cardiovascular events, and hospitalisation. N Engl J Med 2004;351:1296-1305.

- 3 Stevens LA, Coresh J, Green T, Levey AS: Assessing kidney function - measured and estimated glomerular filtration rate. $\mathrm{N}$ Engl J Med 2006;354:2473-2483.

4 Donadio C, Lucchesi A, Ardini M: Cystatin $\mathrm{C}, \beta_{2}$-microglobulin, and retinol binding proteins as indicators of glomerular filtration rate: comparison with plasma creatinine. J Pharm Biomed Anal 2001;24:835842.

5 Levey AS, Berg RL, Gassmann JJ, Hall PM, Walker WG: Creatinine filtration, secretion and excretion during progressive renal disease. Kidney Int 1989;36(suppl 27):S73-S80.

6 National Kidney Foundation: K/DOQI clinical practice guideline to define chronic kidney disease: evaluation, classification and stratification. Am J Kidney Dis 2002;39 (suppl 1):S1-S266.

-7 Froissart M, Rossert J, Jacquot C, Paillard M, Houillier P: Predictive performance of the Modification of Diet in Renal Disease and Cockcroft-Gault equations for estimating renal function. J Am Soc Nephrol 2005;16: 763-773.

8 Poggio ED, Wang X, Greene T, Van Lente F, Hall PM: Performance of the Modification of Diet in Renal Disease and Cockcroft-Gault equations in the estimation of GFR in health and in chronic kidney disease. J Am Soc Nephrol 2005;16:459-466.

-9 Levey AS, Stevens LA, Schmid CH, Schmid $\mathrm{CH}$, Zhang Y, Castro AF, et al: A new equation to estimate glomerular filtration rate: CKD-EPI (Chronic Kidney Disease Epidemiology Collaboration). Ann Intern Med 2009;150:604-612.
10 Randers E, Erlandsen EJ: Serum cystatin C as an endogenous marker of renal function: a review. Clin Chem Lab Med 1999;37:389395.

11 Coll E, Botey A, Alvarez L, Poch E, Quintó L, Saurina A, Vera M, Piera C, Darnell A: Serum cystatin $C$ as a new marker for noninvasive estimation of glomerular filtration rate and as a marker for early renal impairment. Am J Kidney Dis 2000;36:29-34.

12 Dharnidharka VR, Kwon C, Stevens G: Serum cystatin $C$ is superior to serum creatinine as a marker of kidney function: a metaanalysis. Am J Kidney Dis 2002;40:221-226.

13 Hojs R, Bevc S, Antolinc B, Gorenjak M, Puklavec L: Serum cystatin C as an endogenous marker of renal function in the elderly. Int J Clin Pharmacol Res 2004;24:49-54

14 Hojs R, Bevc S, Ekart R, Gorenjak M, Puklavec L: Serum cystatin $\mathrm{C}$ as an endogenous marker of renal function in patients with mild to moderate impaired kidney function. Nephrol Dial Transplant 2006;21:18551862.

15 Grubb A, Nyman U, Bjorak J, Lindström V, Rippe B, Sterner G, Christensson A: Simple cystatin C-based prediction equations for glomerular rate compared with Modification of Diet in Renal Disease prediction equation for adults and the Schwartz and the Counhan-Barratt prediction equations for children. Clin Chem 2005;51:1420-1431.

16 Hoek FJ, Kemperman FA, Krediet RT: A comparison between cystatin C, plasma creatinine and the Cockcroft and Gault formula for the estimation of glomerular filtration rate. Nephrol Dial Transplant 2003;18:20242031.

17 Larsson A, Malm J, Grubb A, Hansson LO: Calculation of glomerular filtration rate expressed in $\mathrm{ml} / \mathrm{min}$ from plasma cystatin $\mathrm{C}$ values in $\mathrm{mg} / \mathrm{l}$. Scand J Clin Lab Invest 2004; 64:25-30.

18 MacIsaac RJ, Tsalamndris C, Thomas MC, Premaratne E, Panagiotopoulos S, Smith TJ, et al: Estimating glomerular filtration rate in diabetes: a comparison of cystatin $\mathrm{C}$ and creatinine-based methods. Diabetologia 2006; 49:1686-1689.
19 Rule AD, Bregstraalh EJ, Slezak JM, Bergert J, Larson TS: Glomerular filtration rate estimated by cystatin $\mathrm{C}$ among different clinical presentations. Kidney Int 2006;69:399-405.

20 Hojs R, Bevc S, Ekart R, Gorenjak M, Puklavec L: Serum cystatin C-based equation compared to serum creatinine-based equations for estimation of glomerular filtration rate in patients with chronic kidney disease. Clin Nephrol 2008;70:10-17.

21 Tidman M, Sjostrom P, Jones I: A comparison of GFR estimating formulae based upon serum cystatin $\mathrm{C}$ and serum creatinine and combination of the two. Nephrol Dial Transplant 2008;23:154-160

22 Mazzachi BC, Peake MJ, Ehrhardt V: Reference range and method comparison studies for enzymatic and Jaffé creatinine assay in plasma and serum and early morning urine. Clin Lab 2000;46:53-55.

23 Blaufox MD, Aurell M, Bubeck B, Fommei E, Piepsz A, Russell C, et al: Report of the Radionuclides in Nephrourology Committee on renal clearance. J Nucl Med 1996;37: 1883-1890.

24 Perkins BA, Nelson RG, Ostrander BE, Blouch KL, Krolewski AS, Mayers BD, et al: Detection of renal function decline in patients with diabetes and normal or elevated GFR by serial measurements of serum cystatin $\mathrm{C}$ concentration: results of 4-year follow-up study. J Am Soc Nephrol 2005;16: 1404-1412.

25 Bland JM, Altman DG: Statistical methods for assessing agreement between two methods of clinical measurement. Lancet 1986;1: 307-310.

-26 Hojs R, Bevc S, Ekart R, Gorenjak M, Puklavec L: Serum cystatin C formulas for prediction of glomerular filtration rate in patients with chronic kidney disease. Nephon Clin Pract 2009;114:118-126.

27 Stevens LA, Coresh J, Feldman HI, Green T, Lash JP, Nelson RG, et al: Evaluation of the Modification of Diet in Renal Disease study equation in a large diverse population. J Am Soc Nephrol 2007;18:2749-2757. 